\title{
Epidermal growth factor receptor and $K R A S$ mutations in lung adenocarcinoma: A retrospective study of the Lebanese population
}

\author{
NAJLA FAKHRUDDIN $^{1,3}$, RAMI MAHFOUZ ${ }^{1}$, FADI FARHAT ${ }^{4}$, ARAFAT TFAYLI $^{2}$, \\ RABAB ABDELKHALIK $^{1}$, MARK JABBOUR ${ }^{1}$, LAMIS YEHIA ${ }^{6}$, \\ ZIYAD MAHFOUD $^{5}$ and GHAZI ZAATARI ${ }^{1}$
}

\begin{abstract}
Departments of ${ }^{1}$ Pathology and Laboratory Medicine and ${ }^{2}$ Hematology-Oncology, American University of Beirut Medical Center, Beirut, Lebanon; Departments of ${ }^{3}$ Pathology and ${ }^{4}$ Hematology-Oncology, Hammoud Hospital University Medical Center, Sidon, Lebanon; ${ }^{5}$ Department of Public Health, Weill Cornell Medical College, Doha, Qatar;

${ }^{6}$ Department of Pathology, Case Western Reserve University School of Medicine, Cleveland, OH, USA
\end{abstract}

Received April 1, 2014; Accepted July 2, 2014

DOI: 10.3892/or.2014.3406

\begin{abstract}
Molecular genetic analysis of epidermal growth factor receptor $(E G F R)$ and Kirsten rat sarcoma viral oncogene $(K R A S)$ mutations in lung adenocarcinoma has become an integral part of lung cancer diagnosis and treatment; however, their prevalence varies with ethnicity. Little is know concerning their prevalence in Arab populations. In the present study, mutational analysis for EGFR and KRAS was performed on two cohorts of the Lebanese population. Lung adenocarcinoma cases (106) underwent mutational analysis for $K R A S$ in exon 2, codon 12 and 13 and exon 3 codon 61 by reverse hybridization using the KRAS 12/13/61 StripAssay ${ }^{\circledR}$. Subsequently, cases with no KRAS mutations underwent $E G F R$ mutational analysis using the $E G F R$ RGQ polymerase chain reaction (PCR) kits for real-time PCR on the Rotor-Gene Q 5-plex HRM. KRAS mutations were detected in $37.7 \%$ of 106 lung adenocarcinomas; $85 \%$ had a $\mathrm{G}>\mathrm{T}$ substitution in codon 12 and 13 of exon 2, and $8.5 \%$ had EGFR mutations with exon 19 deletions $(88.9 \%)$ and one case with L858R substitution in exon 21. EGFR mutations were significantly correlated with females, non-smokers and well differentiation of the tumor. This is the first study in an Arab population that reports the prevalence of both EGFR and KRAS gene mutations in lung adenocarcinoma using very sensitive mutational analysis techniques. Therefore, EGFR reflex testing should be implemented in the management of lung adenocarcinomas,
\end{abstract}

Correspondence to: Dr Najla Fakhruddin, Department of Pathology and Laboratory Medicine, American University of Beirut, P.O. Box 11-0236, Riad El-Solh, Beirut 1107 2020, Lebanon

E-mail:nf21@aub.edu.lb

Key words: lung adenocarcinoma, EGFR, KRAS, mutational analysis, reverse hybridization while KRAS testing must await the identification of effective targeted therapy.

\section{Introduction}

Lung cancer is the leading cause of cancer-related deaths in males and second after breast cancer in females. Its incidence is high and has a global age-standardized rate (ASR) of 47.4/100,000 and 18.6/100,000 for males and females, respectively (1). In the Arab countries, the incidence of lung cancer ranks after prostate, colon or bladder cancer in males and after breast and cervical cancer in females (2). The ASRs are 13.44/100,000 and 2.91/100,000 for males and females, respectively, but the highest incidence is reported in Tunisia followed by Bahrain. However, the largest number of cases occurs in North African countries, Egypt (20.6\%), Morocco (20.1\%), Algeria (15.4\%) and Tunisia (10\%), reflective of their high population. As for Lebanon, lung cancer incidence ranks third after Tunisia and Bahrain in males and second after Bahrain in females (3). The reported ASRs for lung adenocarcinoma in Lebanon are 27.3/100,000 and 10.2/100,000 for males and females, respectively (4).

For several decades lung cancer has been treated as a single disease, yet with greater knowledge of its molecular biology lung cancer is now considered a heterogeneous disease. Most important was the discovery of the association of epidermal growth factor receptor $(E G F R)$ gene mutations and anaplastic lymphoma kinase $(A L K)$ gene fusion with lung adenocarcinoma histology. These genetic aberrations have been linked to specific ethnicities and gender in never-smokers and have shown a good response to tyrosine kinase inhibitors (5-9). Consequently, mutational analysis of EGFR and EML-ALK has become a cornerstone in the management of patients with lung adenocarcinoma (10). Moreover, downstream of the EGFR pathway is the Kirsten rat sarcoma viral oncogene, or $\mathrm{v}$-Ki-ras2 homolog $(K R A S)$, known to occur in a wide range of cancers, with the highest prevalence in pancreatic $(\sim 90 \%)$, 
colorectal $(\sim 60 \%)$ and primary lung adenocarcinomas $(\sim 60 \%)$, which can be mutated in lung cancer (11). When this mutation is detected, it is mutually exclusive of $E G F R$ mutations but only rare and exceptional cases demonstrate both mutations (13), and a number of studies correlate its presence with resistance to anti-EGFR therapy and poor patient prognosis (11).

Lung cancer is notoriously correlated with smoking; therefore, the US and a number of European countries have implemented tobacco control programs and attained a decreased incidence worldwide $(14,15)$. Unfortunately, in the Arab countries the incidence is increasing since smoking habits are increasing particularly among females and youth (3). Furthermore, in the hope of decreasing cancer-related mortality, almost all ethnic groups have been investigated for $E G F R$ and KRAS gene mutation frequency in lung adenocarcinoma $(16,17)$, but such a study has not been conducted in any Arab population including the Lebanese. Therefore, we aimed to evaluate the prevalence of KRAS and EGFR gene mutations in two Lebanese lung adenocarcinoma cohort groups and to correlate the findings with the clinical and pathologic features, including age, gender, smoking history and histological grade.

\section{Materials and methods}

The Institutional Review Boards of the American University of Beirut Medical Center and Hammoud Hospital University Medical Center approved this study. Both boards waived the need for written patient informed consents.

Patient selection. Patient cases (242) diagnosed clinically with primary lung adenocarcinoma (AC) and 150 with non-small cell carcinoma-not otherwise specified (NSCLC-NOS) were retrieved from the archives of the Pathology Departments at the American University of Beirut Medical Center and Hammoud Hospital University Medical Center in Lebanon from the year 2001 to 2010 . Of the 150 NSCLC-NOS cases, 91 had an adequate tumor size $(>1 \mathrm{~mm})$ for further subtyping by immunohistochemical staining and 37 cases were diagnosed as 'favoring primary lung AC'. Moreover, to ensure good quality and quantity of extracted DNA for mutational analysis, all 279 primary lung $\mathrm{AC}$ cases were then evaluated microscopically for tumor size. The cases with $>200$ tumor cells were included; thus, 106 primary lung AC cases were selected for EGFR and $K R A S$ mutational analysis. The clinicopathologic information pertaining to patient age at diagnosis, gender, history of smoking, grade and TNM stage was retrieved for all cases, and none of the patients in this study received chemotherapy prior to specimen resection (lobectomy) or biopsy.

Immunohistochemistry. Three histological sections of $3-\mu \mathrm{m}$ thickness were prepared from formalin-fixed paraffin-embedded (FFPE) tissue blocks of the NSCLC-NOS cases. Immunomarker detection was performed using antibodies against TTF-1 (thyroid transcription factor-1) (1:200 dilution; Novocastra; SPT24), napsin A (1:400 dilution; Novocastra; IP64) and p63 (Ready-to-use; Novocastra; 7JUL). Positive staining for TTF-1 and/or napsin A was used for identifying $\mathrm{AC}$ and $\mathrm{p} 63$ for squamous cell carcinoma. The immunomarkers were considered positive if at least $10 \%$ of the tumor cells stained. Cases with $<10 \%$ staining

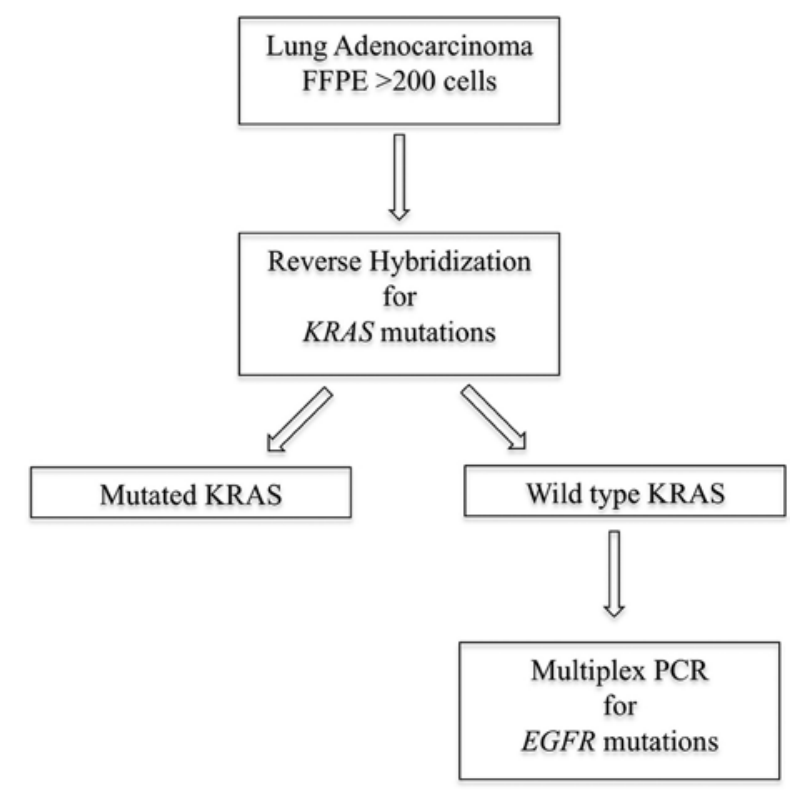

Figure 1. Algorithm for lung adenocarcinoma molecular analysis. FFPE, formalin-fixed paraffin-embedded.

and no focal areas of positive staining were interpreted as negative. Appropriate positive and negative controls were included. Immunostaining by TTF-1 of entrapped normal lung epithelium or napsin A of pulmonary macrophages was ignored. Immunohistochemistry was performed using the Leica Bond-Max autostainer (Leica Microsystems Inc., Buffalo Grove, IL, USA) with the manufacturer's preset timed reagents.

Mutational analysis for KRAS and EGFR. FFPE tissue blocks of the included 106 lung adenocarcinoma cases were collected for KRAS and EGFR mutational analysis according to the algorithm (Fig. 1).

DNA extraction from FFPE. Eight 10- $\mu \mathrm{m}$ FFPE tissue ribbons were obtained from each block, and lysis was allowed overnight at $65^{\circ} \mathrm{C}$ with $1.5 \mu \mathrm{l}$ proteinase $\mathrm{K}(20 \mathrm{mg} / \mathrm{ml})$ and $400 \mu \mathrm{l}$ cell lysis solution (Qiagen; 158906). DNA was extracted following a standard protocol and quantified using the NanoDrop ND-1000 spectrophotometer. The resultant DNA was stored at $4^{\circ} \mathrm{C}$ until utilized for reverse hybridization and multiplex real-time polymerase chain reaction (PCR) procedures.

Reverse hybridization for detection of KRAS mutations. Detection of KRAS mutations in exon 2, codon 12 and 13 and exon 3 codon 61 was performed by reverse hybridization using the $K R A S$ 12/13/61 StripAssay ${ }^{\circledR}$ (ViennaLab Diagnostics $\mathrm{GmbH}$, Vienna, Austria). This technique involves three steps: PCR amplification using biotinylated oligonucleotide primers, hybridization of the amplified products to a strip containing allele-specific oligonucleotide probes immobilized as an array of parallel lines and placed in a shaking water bath at $45^{\circ} \mathrm{C}$ and identification of bound biotinylated sequences using streptavidin-alkaline phosohatase and color substrates performed at room temperature. Bands were then analyzed visually. Cases that did not exhibit these mutations were then submitted for 
Table I. Overall clinical characteristics and association with $K R A S$ and EGFR mutations.

\begin{tabular}{|c|c|c|c|c|c|c|c|}
\hline Variables & $\begin{array}{c}\text { Overall } \\
\mathrm{n}(\%)\end{array}$ & $\begin{array}{c}\text { KRAS } \\
\text { mutation } \\
\mathrm{n}(\%)\end{array}$ & $\begin{array}{c}\text { No } K R A S \\
\text { mutation } \\
\text { n }(\%)\end{array}$ & P-value & $\begin{array}{c}E G F R \\
\text { mutation } \\
\mathrm{n}(\%)\end{array}$ & $\begin{array}{c}\text { No } E G F R \\
\text { mutation } \\
\mathrm{n}(\%)\end{array}$ & P-value \\
\hline Age (years) & & & & 0.172 & & & 0.232 \\
\hline Mean \pm SD & $62.1 \pm 10.4$ & $64.0 \pm 8.7$ & $61.0 \pm 11.2$ & & $57.8 \pm 8.8$ & $62.3 \pm 10.4$ & \\
\hline Gender & & & & 0.942 & & & $0.005^{\mathrm{a}}$ \\
\hline Female & $34(32.1)$ & $13(32.5)$ & $21(31.8)$ & & $7(77.8)$ & $27(28.4)$ & \\
\hline Male & $72(67.9)$ & $27(67.5)$ & $45(68.2)$ & & $2(22.2)$ & $70(71.6)$ & \\
\hline Tumor differentiation & & & & 0.207 & & & $<0.001^{\mathrm{a}}$ \\
\hline Poor & $66(62.3)$ & $25(62.5)$ & $41(62.1)$ & & $5(55.6)$ & $61(62.9)$ & \\
\hline Moderate & $35(33.0)$ & $15(37.5)$ & $20(30.3)$ & & $0 \quad(0.0)$ & $35(36.1)$ & \\
\hline Well & $5 \quad(4.7)$ & $0 \quad(0.0)$ & $5 \quad(7.6)$ & & $4(44.4)$ & $1 \quad(1.0)$ & \\
\hline Smoking & & & & 0.286 & & & $0.003^{\mathrm{a}}$ \\
\hline Yes & $59(55.7)$ & $23(57.5)$ & $36(54.6)$ & & $1(11.1)$ & $58(59.8)$ & \\
\hline No & $18(17.0)$ & $4(10.0)$ & $14(21.2)$ & & $5(55.6)$ & $13(13.4)$ & \\
\hline Not available & $29(27.4)$ & $13(32.5)$ & $16(24.2)$ & & $3(33.3)$ & $26(26.8)$ & \\
\hline Tumor size $(\mathrm{T})(\mathrm{cm})$ & & & & 0.389 & & & 0.881 \\
\hline$\leq 3$ & $12(11.3)$ & $6(15.0)$ & $6 \quad(9.1)$ & & $1(11.1)$ & $11(11.3)$ & \\
\hline$>3$ & $31(29.3)$ & $9(22.5)$ & $22(33.3)$ & & $2(22.2)$ & $29(29.9)$ & \\
\hline Not available & $63(59.4)$ & $25(62.5)$ & $38(57.6)$ & & $6(66.7)$ & $57(58.8)$ & \\
\hline Lymph node (N) & & & & 0.879 & & & 0.424 \\
\hline Yes & 19 (17.9) & $7(17.5)$ & $12(18.2)$ & & $0 \quad(0.0)$ & $19(19.6)$ & \\
\hline No & $21(19.8)$ & $7(17.5)$ & $14(21.2)$ & & $2(22.2)$ & 19 (19.6) & \\
\hline Not available & $66(62.3)$ & $26(65.0)$ & $40(60.6)$ & & $7(77.8)$ & $59(60.8)$ & \\
\hline Metastasis (M) & & & & 0.658 & & & 0.792 \\
\hline Yes & $20(18.9)$ & $6(15.0)$ & $14(21.2)$ & & $2(22.2)$ & $18(18.6)$ & \\
\hline No & $23(21.7)$ & $10(25.0)$ & $13(19.7)$ & & $1(11.1)$ & $22(22.7)$ & \\
\hline Not available & $63(59.4)$ & $24(60.0)$ & $39(59.1)$ & & $6(66.7)$ & $57(58.8)$ & \\
\hline
\end{tabular}

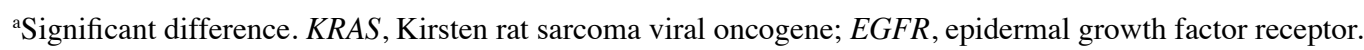

EGFR exons 18-21 mutational analysis, knowing that $K R A S$ and $E G F R$ mutations are predominantly mutually exclusive.

Multiplex real-time PCR for detection of EGFR mutations. $E G F R$ mutational analysis was performed using the EGFR RGQ PCR kits (Qiagen, Valencia, CA, USA), that enables detection of 29 somatic mutations in the EGFR gene including: 19 deletions in exon 19, T790M-exon 20, L858R-exon 21, L861Q-exon 21, G719X-exon 18, S768I-exon 20 and 3 insertions in exon 20. The kit utilizes two technologies, amplification refractory mutation system (ARMS) technology and Scorpions dual primer probes available for detection of EGFR mutations using real-time PCR on the Rotor-Gene Q 5-plex HRM instrument (Qiagen). This analysis is performed in two steps: the first step is to perform a control assay in order to assess the total DNA in the sample and the second step is to complete the assay for the presence or absence of mutated DNA. This procedure was completed as per the manufacturer's instructions manual. We considered this technology because of its high sensitivity particularly for samples with low levels of tumor DNA, such as in small lung biopsy samples.
Statistical analysis. Age, gender, smoking history, grade and TNM stage were summarized using means and standard deviation for age and frequency distribution for the other 4 variables. Those variables were compared between patients with KRAS mutation and those without KRAS mutation using the independent t-test for age (or Wilcoxon rank sum test for small sample size) and the Chi-squared test or Fisher's exact test (when cell counts were small) for the other 4 variables. Similar comparisons were made between patients with an EGFR mutation and those without mutations.

\section{Results}

The overall clinical and pathological data of the 106 primary lung adenocarcinoma cases demonstrated a mean age of 62 years and a male to female ratio of 2:1. The majority of patients were smokers (55.7\%), although we could not determine the smoking history data for $27.7 \%$. A total of $56.2 \%$ of the tumors were poorly differentiated when applying the threetier grading system. TNM staging data were available for $45 \%$ of the cases, which limited our statistical analysis, but more 
Table II. Summary of KRAS mutations in exon 2.

\begin{tabular}{lc}
\hline KRAS mutation & No. of cases \\
\hline c.34G $>$ T, p.G12C & 19 \\
c.34G $>$ A, p.G12C & 1 \\
c.35G >C, p.G12A & 11 \\
c.35G $>$ A, p.G12A & 2 \\
c.35G $>$ A, p.G12D & 5 \\
c.35G $>$ T, p.G12V & 2 \\
c.37G $>$ T, p.G13C & 2 \\
c.38G $>$ A, p.G13A & 2 \\
c.38G $>$ A, p.G13D & 2 \\
\hline
\end{tabular}

$K R A S$, Kirsten rat sarcoma viral oncogene.

Table III. Summary of EGFR mutations.

\begin{tabular}{lc}
\hline EGFR mutation & No. of cases \\
\hline Exon 18 & 0 \\
Exon 19 deletions & 8 \\
Exon 20 & 0 \\
L858R-exon 21 & 1 \\
\hline
\end{tabular}

$E G F R$, epidermal growth factor receptor.

tumors had a size larger than $3 \mathrm{~cm}$, while approximately half of the cases had lymph node and/or distant metastasis (Table I).

The prevalence of KRAS mutations was detected in $37.7 \%$ of the primary lung AC cases. The majority (85\%) had a $\mathrm{G}>\mathrm{T}$ substitutions in codon 12 of exon 2 and 6 cases had this substitution in codon 13 (Table II). An A>G substitution in codon 61 of exon 3 was detected in one case. All of the KRAS mutations were single except for 5 cases that exhibited double mutations. The KRAS mutations were predominant in males (67.5 vs. $32.5 \%$ in females) and in smokers (57.5 vs. $10.0 \%$ in non-smokers); however, no statistical significance could be concluded ( $\mathrm{p}=0.942$ and $\mathrm{p}=0.286$, respectively). The majority of the $K R A S$-mutated tumors were poorly differentiated $(62.5 \%)$ and had a tumor size larger than $3 \mathrm{~cm}$, but the frequency of lymph node or distant metastasis was not significantly higher when compared to the lung adenocarcinoma cases with no KRAS mutation (Table I).

EGFR mutations were detected in $9(8.5 \%)$ of the lung adenocarcinoma patients with no KRAS mutations. The most common mutations ( 8 cases, $88.9 \%$ ) were deletion in exon 19 while one case had a substitution L858R in exon 21 (Table III). Predominance of EGFR mutations was significant in females $(\mathrm{p}=0.005)$, non-smokers $(\mathrm{p}=0.003)$ and well differentiated tumors $(\mathrm{p}<0.001)$. TNM data were not available for all the 9 cases; therefore, we could not draw a significant correlation (Table I).

In summary, we identified mutations in $46.2 \%$ of the lung adenocarcinoma cases distributed into $37.7 \%$ with $K R A S$ mutations and $8.5 \%$ with EGFR mutations (Table IV).
Table IV. Summary of the EGFR and KRAS mutations in primary adenocarcinoma.

\begin{tabular}{lccc}
\hline & \multicolumn{3}{c}{ Mutations } \\
\cline { 2 - 4 } & $\begin{array}{c}E G F R \\
\mathrm{n}(\%)\end{array}$ & $\begin{array}{l}\text { KRAS } \\
\mathrm{n}(\%)\end{array}$ & $\begin{array}{l}\text { Total } \\
\mathrm{n}(\%)\end{array}$ \\
\hline Cases & $9(8.5)$ & $40(37.7)$ & $49(45.2)$
\end{tabular}

$K R A S$, Kirsten rat sarcoma viral oncogene; $E G F R$, epidermal growth factor receptor.

\section{Discussion}

Molecular genetic analysis of lung adenocarcinoma has become an integral part of lung cancer diagnosis and present treatment $(18,19)$. The most commonly detected driver mutations are those involving KRAS, EGFR and EML4-ALK genes. Moreover, $E G F R$ tyrosine kinase inhibitors (TKIs), gefitinib, erlotinib and afatinib, are considered as first-line targeted therapy for advanced (locally or metastatic) lung adenocarcinoma. However, the prevalence of these aberrations varies with gender, ethnicity and smoking history (20). Consequently, lung adenocarcinomas have been extensively profiled for genetic aberrations in most ethnic groups. In the Arab population, only one study evaluated EGFR genetic aberrations in 34 Saudi lung cancer patients (21). In the present study, 106 cases of lung adenocarcinomas from Lebanon were analyzed for mutations in KRAS and EGFR.

$E G F R$ mutations were detected in $8.5 \%$ of the lung adenocarcinomas, a frequency higher than that in the Saudi population, comparable to that of some European countries, but much lower than that of Asian countries. The highest reported frequency of $E G F R$ mutations is in Asian, non-smoker females (Taiwan, 57.3\%) (22). However, the Europeans reported much lower frequencies and Szumera-Ciećkiewicz et al reviewed the results from 19 European studies and showed a range of $2.6 \%$ (in Italy) to $39 \%$ (in Germany) (23). In the US, a study of 3026 cases by Dogan et al demonstrated a frequency of $20 \%$ (24) and Reinersman et al reported a frequency of $19 \%$ in African-Americans (25). In Latin America, the average frequency is $33.2 \%$ with the lowest in Argentina (19.3\%) and the highest in Peru (67\%). This reported frequency is correlated with the high rate of Asian migration (26). To the best of our knowledge, in the Middle East and the Levant countries, only one study from Saudi Arabia has been published. This study applied direct DNA sequencing to 34 lung cancer cases and detected the EGFR mutation in one lung adenocarcinoma (3\%) (21).

The analysis of EGFR mutation subtypes demonstrated a predominance of deletions in exon 19 and only one of the 9 cases had an L858R substitution in exon 21. These findings are comparable to the reported frequency of EGFR mutation subtypes: in-frame deletions in exon 19 (44\% of all mutations), missense point mutations (L858R substitution) in exon 21 (41\% of all mutations), in-frame duplications/insertions in exon 20 (5\% of all mutations) and G719X (X indicates A, C or S) substitution in exon 18 (4\% of all mutations) (27). It is impor- 
Table V. Frequency of KRAS and EGFR mutations reported from different countries and ethnicities.

\begin{tabular}{|c|c|c|c|c|c|}
\hline Country & $K R A S(\%)$ & $\operatorname{EGFR}(\%)$ & Smoking history & $\mathrm{N}^{\mathrm{a}}$ & Year (ref.) \\
\hline Australia & 17.0 & & & 108 & $1998(38)$ \\
\hline Saudi Arabia & & 2.94 & & 34 & $2006(21)$ \\
\hline Hong Kong & 9.8 & 54.0 & Correlated & 215 & $2006(39)$ \\
\hline Korea & 7.3 & 17.4 & & 55 & $2007(40)$ \\
\hline USA & 21.2 & & Not correlated & 482 & $2008(31)$ \\
\hline Taiwan & 5.03 & 57.3 & Not correlated & 159 & $2008(22)$ \\
\hline Japan & 12.6 & 49.4 & & 254 & $2009(41)$ \\
\hline Korea & 9.6 & 24.0 & & 94 & $2009(42)$ \\
\hline Italy & 17.9 & 12.6 & & 411 & $2009(43)$ \\
\hline USA & 23.0 & 10.0 & Correlated & 345 & $2010(36)$ \\
\hline Argentina & & 19.3 & Correlated & 244 & $2011(26)$ \\
\hline Columbia & 17.1 & 24.8 & Correlated & 322 & $2011(26)$ \\
\hline Mexico & 16.0 & 31.2 & Correlated & 381 & $2011(26)$ \\
\hline Peru & 16.8 & 67.0 & Correlated & 381 & $2011(26)$ \\
\hline China & 8.0 & 41.0 & Correlated & 861 & $2012(44)$ \\
\hline USA & 26.0 & 20.0 & Correlated & $2529 / 3026^{b}$ & $2012(24)$ \\
\hline Japan & 16.5 & 41.7 & Correlated & 182 & $2012(45)$ \\
\hline Netherlands & 36.9 & 10.6 & Correlated & 662 & $2012(46)$ \\
\hline Brazilian & 14.6 & 30.4 & Correlated & 207 & $2012(47)$ \\
\hline China & 5.9 & & & 1935 & $2013(48)$ \\
\hline Czech Republic & 21.0 & & & 233 & 2013 (49) \\
\hline Western Turkey & & 42.6 & Correlated & 48 & $2013(50)$ \\
\hline Europe & & $2.6-39^{c}$ & Correlated & $23-147$ & $2013(23)$ \\
\hline Korea & & 39.0 & Correlated & 502 & $2013(51)$ \\
\hline Lebanon & 37.7 & 8.5 & Not correlated & 106 & Present study \\
\hline
\end{tabular}

${ }^{a} \mathrm{~N}$, no. of cases evaluated for $K R A S$ and/or $E G F R$; ${ }^{2} 2529$ : for $K R A S, 3026$ : for $E G F R$; ' Lowest in Italy, highest in Germany. KRAS, Kirsten rat sarcoma viral oncogene; $E G F R$, epidermal growth factor receptor.

tant to subtype these mutations since they respond differently to EGFR TKIs (28). For example, the T790M mutation in exon 20 correlates with drug resistance and relapse (29). In addition, we demonstrated a significant correlation between EGFR mutations and females, non-smokers and well differentiation of the tumor. These findings are in concordance with the reported prevalence of these mutations in females more than in males and in never-smokers than in smokers and to their correlation with a better prognosis (30).

$K R A S$ mutations were detected in $37.7 \%$ of the lung adenocarcinomas. Similar to EGFR mutations, the prevalence of $K R A S$ mutations in lung adenocarcinoma varies with ethnic groups as well, but is generally mutually exclusive with EGFR mutations $(13,31)$. An overview of KRAS and EGFR mutation frequency from different countries presented in Table $\mathrm{V}$ demonstrates an inverse EGFR mutation frequency as compared to that of $K R A S$. The lowest values were reported in Asians (Taiwan: KRAS, 5.03\%; EGFR, 57.3\%), while the highest $K R A S$ prevalence was reported in Europeans (The Netherlands: KRAS, $36.9 \%$; EGFR, $10.6 \%$ ).

In addition, we found that $K R A S$ mutations were predominantly in exons 2 and 3 with $85 \%$ involving codon 12, thus concordant with that reported by Bos, where $97 \%$ of KRAS mutation subtypes are substitutions of $G \rightarrow T$ and $G \rightarrow C$ in codon 12 of exon 2 in addition to the missense point mutations in codons 61 that prevent GTP cleaving, thus transforming the gene into an oncogene (32). However, we could not demonstrate a correlation between smoking and the type of substitution and the subtype of the mutation. Such a correlation was described by Riely et al where they demonstrated that the $G \rightarrow T$ and $G \rightarrow C$ transversions are present in both smokers and non-smokers, while a $G \rightarrow A$ transversion is more common in non-smokers (12). Moreover, we detected more KRAS mutations in males, smokers and poorly differentiated tumors, but this observation did not demonstrate a statistically significant correlation. Several other studies have shown that KRAS mutations are higher in males and smokers as compared to females and never-smokers (33), predict a worse prognosis $(34,35)$, and show a low response to adjuvant chemotherapy and EGFR-TKI treatment in metastatic lung adenocarcinoma (7). Unfortunately, because it leads to loss of enzymatic activity, effective targeted therapy is more difficult to achieve as compared to a gain of functional mutation. Currently, clinical trials targeting downstream effector molecules are being conducted, but no effective targeted therapy against KRAS mutations has been achieved thus far. 
Two mutational analysis techniques were used in this study. The Scorpion amplified refractory mutation system (ARMS) multiplex real-time PCR was used for the detection of EGFR mutations. Although this technique does not detect mutations comprehensively, it covers all the common 29 EGFR mutations in exons $18-21$. It is highly sensitive (1\%) as compared to direct Sanger sequencing (25\%) of mutant DNA (36). For $K R A S$ mutations we used reverse hybridization (StripAssay, ViennaLab), which is considered most analytically sensitive when compared to direct sequencing, pyrosequencing, high resolution melting analysis and the TheraScreen DxS kit (37). This technique can detect 13 mutations in the KRAS codon 12,13 and 61 . The high sensitivity of both techniques was necessary to overcome the tissue limitation of small lung biopsy material that constituted the majority of our cases. However, some biopsy material was too scant to be included in this study thus constituting a limitation for this study. In addition, the unavailability of adequate smoking history data for all cases, and being retrospective in nature are additional limitations.

In summary, this is the first study in an Arab population to report the prevalence of both $E G F R$ and $K R A S$ gene mutations in lung adenocarcinoma using sensitive mutational analysis techniques. We showed that the frequency of EGFR in lung adenocarcinoma was $8.5 \%$ and that it was more common in women, non-smokers and well-differentiated tumors. In addition, we found that KRAS was highly prevalent in the Lebanese population, but we could not significantly correlate it with smoking; however, it remains a possible major cause. Therefore, we conclude that EGFR reflex testing should be implemented as per the recommendation of the College of American Pathologists, International Association for the Study of Lung Cancer and Association for Molecular Pathology (10). While KRAS testing is useful for understanding the molecular biology of adenocarcinoma, the clinical utilization of this information must await the identification of effective targeted therapy.

\section{Acknowledgements}

The authors are grateful for the generous funding support provided by the Lebanese National Council for Scientific Research (LNCSR), grant no. PALM. GZ.09.

\section{References}

1. Jemal A, Center MM, DeSantis C and Ward EM: Global patterns of cancer incidence and mortality rates and trends. Cancer Epidemiol Biomarkers Prev 19: 1893-1907, 2010.

2. Salim EI, Moore MA, Al-Lawati JA, et al: Cancer epidemiology and control in the Arab world - past, present and future. Asian Pac J Cancer Prev 10: 3-16, 2009.

3. Salim EI, Jazieh AR and Moore MA: Lung cancer incidence in the Arab league countries: risk factors and control. Asian Pac J Cancer Prev 12: 17-34, 2011.

4. Ministry of Public Health (MOPH) L: Literature review report on selected diseases in Lebanon, 2004.

5. Lynch TJ, Bell DW, Sordella R, et al: Activating mutations in the epidermal growth factor receptor underlying responsiveness of non-small-cell lung cancer to gefitinib. N Engl J Med 350 2129-2139, 2004.

6. Paez JG, Janne PA, Lee JC, et al: EGFR mutations in lung cancer: correlation with clinical response to gefitinib therapy. Science 304: 1497-1500, 2004.
7. Eberhard DA, Johnson BE, Amler LC, et al: Mutations in the epidermal growth factor receptor and in KRAS are predictive and prognostic indicators in patients with non-small-cell lung cancer treated with chemotherapy alone and in combination with erlotinib. J Clin Oncol 23: 5900-5909, 2005.

8. Wang Y, Schmid-Bindert G and Zhou C: Erlotinib in the treatment of advanced non-small cell lung cancer: an update for clinicians. Ther Adv Med Oncol 4: 19-29, 2012.

9. Ahmed SM and Salgia R: Epidermal growth factor receptor mutations and susceptibility to targeted therapy in lung cancer. Respirology 11: 687-692, 2006.

10. Lindeman NI, Cagle PT, Beasley MB, et al: Molecular testing guideline for selection of lung cancer patients for EGFR and ALK tyrosine kinase inhibitors: guideline from the College of American Pathologists, International Association for the Study of Lung Cancer, and Association for Molecular Pathology. Arch Pathol Lab Med 137: 828-860, 2013.

11. Kiaris H and Spandidos D: Mutations of ras genes in human tumours (Review). Int J Oncol 3: 413-421, 1995.

12. Riely GJ, Marks J and Pao W: KRAS mutations in non-small cell lung cancer. Proc Am Thorac Soc 6: 201-205, 2009.

13. Roberts PJ, Stinchcombe TE, Der CJ and Socinski MA: Personalized medicine in non-small-cell lung cancer: is KRAS a useful marker in selecting patients for epidermal growth factor receptor-targeted therapy? J Clin Oncol 28: 4769-4777, 2010.

14. Centers for Disease Control and Prevention (CDC): Lung cancer rates decline nationwide, 2011. http://www.cdc.gov/media/ releases/2011/p0915_lung_cancer.html.

15. Cancer Research UK: Lung cancer incidence statistics, 2013. http://www.cancerresearchuk.org/cancer-info/cancerstats/types/ lung/incidence/uk-lung-cancer-incidence-statistics.

16. Underwood JM, Townsend JS, Tai E, et al: Racial and regional disparities in lung cancer incidence. Cancer 118: 1910-1918, 2012.

17. Zhou W and Christiani DC: East meets West: ethnic differences in epidemiology and clinical behaviors of lung cancer between East Asians and Caucasians. Chin J Cancer 30: 287-292, 2011.

18. Greulich $\mathrm{H}$ : The genomics of lung adenocarcinoma: opportunities for targeted therapies. Genes Cancer 1: 1200-1210, 2010.

19. Zhou C, Wu YL, Chen G, et al: Erlotinib versus chemotherapy as first-line treatment for patients with advanced EGFR mutation-positive non-small-cell lung cancer (OPTIMAL, CTONG-0802): a multicentre, open-label, randomised, phase 3 study. Lancet Oncol 12: 735-742, 2011.

20. Travis WD, Brambilla E, Noguchi M, et al: International Association for the Study of Lung Cancer/American Thoracic Society/European Respiratory Society International Multidisciplinary Classification of Lung Adenocarcinoma. J Thorac Oncol 6: 244-285, 2011.

21. Al-Kuraya K, Siraj AK, Bavi P, et al: High epidermal growth factor receptor amplification rate but low mutation frequency in Middle East lung cancer population. Hum Pathol 37: 453-457, 2006.

22. Wu CC, Hsu HY, Liu HP, et al: Reversed mutation rates of KRAS and $E G F R$ genes in adenocarcinoma of the lung in Taiwan and their implications. Cancer 113: 3199-3208, 2008.

23. Szumera-Cieckiewicz A, Olszewski WT, Tysarowski A, et al: EGFR mutation testing on cytological and histological samples in non-small cell lung cancer: a Polish, single institution study and systematic review of European incidence. Int J Clin Exp Pathol 6: 2800-2812, 2013 .

24. Dogan S, Shen R, Ang DC, et al: Molecular epidemiology of $E G F R$ and $K R A S$ mutations in 3,026 lung adenocarcinomas: higher susceptibility of women to smoking-related $K R A S$-mutant cancers. Clin Cancer Res 18: 6169-6177, 2012.

25. Reinersman JM, Johnson ML, Riely GJ, et al: Frequency of $E G F R$ and $K R A S$ mutations in lung adenocarcinomas in African Americans. J Thorac Oncol 6: 28-31, 2011.

26. Arrieta O, Cardona AF, Federico Bramuglia G, et al: Genotyping non-small cell lung cancer (NSCLC) in Latin America. J Thorac Oncol 6: 1955-1959, 2011.

27. Gazdar AF, Shigematsu H, Herz J and Minna JD: Mutations and addiction to EGFR: the Achilles 'heal' of lung cancers? Trends Mol Med 10: 481-486, 2004.

28. Kim YT, Kim TY, Lee DS, et al: Molecular changes of epidermal growth factor receptor (EGFR) and KRAS and their impact on the clinical outcomes in surgically resected adenocarcinoma of the lung. Lung Cancer 59: 111-118, 2008.

29. Godin-Heymann N, Bryant I, Rivera MN, et al: Oncogenic activity of epidermal growth factor receptor kinase mutant alleles is enhanced by the T790M drug resistance mutation. Cancer Res 67: 7319-7326, 2007. 
30. Pao W, Miller V,Zakowski M, et al: EGF receptor gene mutations are common in lung cancers from 'never smokers' and are associated with sensitivity of tumors to gefitinib and erlotinib. Proc Natl Acad Sci USA 101: 13306-13311, 2004.

31. Riely GJ, Kris MG, Rosenbaum D, et al: Frequency and distinctive spectrum of KRAS mutations in never smokers with lung adenocarcinoma. Clin Cancer Res 14: 5731-5734, 2008.

32. Bos JL: ras oncogenes in human cancer: a review. Cancer Res 49: 4682-4689, 1989.

33. Okudela K, Woo T and Kitamura H: KRAS gene mutations in lung cancer: particulars established and issues unresolved. Pathol Int 60: 651-660, 2010.

34. Siegfried JM, Gillespie AT, Mera R, et al: Prognostic value of specific KRAS mutations in lung adenocarcinomas. Cancer Epidemiol Biomarkers Prev 6: 841-847, 1997.

35. Johnson ML, Sima CS, Chaft J, et al: Association of KRAS and EGFR mutations with survival in patients with advanced lung adenocarcinomas. Cancer 119: 356-362, 2013.

36. Dacic S: EGFR assays in lung cancer. Adv Anat Pathol 15: 241-247, 2008.

37. Jancik S, Drabek J, Berkovcova J, et al: A comparison of direct sequencing, pyrosequencing, high resolution melting analysis, TheraScreen DxS, and the K-ras StripAssay for detecting KRAS mutations in non small cell lung carcinomas. J Exp Clin Cancer Res 31: 79, 2012.

38. Fong KM, Zimmerman PV and Smith PJ: KRAS codon 12 mutations in Australian non-small cell lung cancer. Aust NZ J Med 28: 184-189, 1998.

39. Tam IY, Chung LP, Suen WS, et al: Distinct epidermal growth factor receptor and $K R A S$ mutation patterns in non-small cell lung cancer patients with different tobacco exposure and clinicopathologic features. Clin Cancer Res 12: 1647-1653, 2006.

40. Bae NC, Chae MH, Lee MH, et al: EGFR, ERBB2, and KRAS mutations in Korean non-small cell lung cancer patients. Cancer Genet Cytogenet 173: 107-113, 2007.

41. Kosaka T, Yatabe Y, Onozato R, Kuwano H and Mitsudomi T: Prognostic implication of EGFR, KRAS, and TP53 gene mutations in a large cohort of Japanese patients with surgically treated lung adenocarcinoma. J Thorac Oncol 4: 22-29, 2009.
42. Jang TW, Oak CH, Chang HK, Suo SJ and Jung MH: EGFR and KRAS mutations in patients with adenocarcinoma of the lung. Korean J Intern Med 24: 48-54, 2009.

43. Boldrini L, Ali G, Gisfredi S, et al: Epidermal growth factor receptor and K-RAS mutations in 411 lung adenocarcinoma: A population-based prospective study. Oncol Rep 22: 683-691, 2009.

44. Xu J, He J, Yang H, et al: Somatic mutation analysis of EGFR, KRAS, BRAF and PIK3CA in 861 patients with non-small cell lung cancer. Cancer Biomark 10: 63-69, 2011.

45. Kakegawa S, Shimizu K, Sugano M, et al: Clinicopathological features of lung adenocarcinoma with KRAS mutations. Cancer 117: 4257-4266, 2011.

46. Smits AJ, Kummer JA, Hinrichs JW, et al: EGFR and KRAS mutations in lung carcinomas in the Dutch population: increased $E G F R$ mutation frequency in malignant pleural effusion of lung adenocarcinoma. Cell Oncol 35: 189-196, 2012.

47. Bacchi CE, Ciol H, Queiroga EM, Benine LC, Silva LH and Ojopi EB: Epidermal growth factor receptor and $K R A S$ mutations in Brazilian lung cancer patients. Clinics 67: 419-424, 2012.

48. Guan JL, Zhong WZ, An SJ, et al: KRAS mutation in patients with lung cancer: a predictor for poor prognosis but not for EGFR-TKIs or chemotherapy. Ann Surg Oncol 20: 1381-1388, 2013.

49. Fiala O, Pesek M, Finek J, Benesova L, Belsanova B and Minarik M: The dominant role of $\mathrm{G} 12 \mathrm{C}$ over other $K R A S$ mutation types in the negative prediction of efficacy of epidermal growth factor receptor tyrosine kinase inhibitors in non-small cell lung cancer. Cancer Genet 206: 26-31, 2013.

50. Unal OU, Oztop I, Calibasi G, et al: Relationship between epidermal growth factor receptor gene mutations and clinicopathological features in patients with non-small cell lung cancer in western Turkey. Asian Pac J Cancer Prev 14: 37053709, 2013.

51. Choi YL, Sun JM, Cho J, et al: EGFR mutation testing in patients with advanced non-small cell lung cancer: a comprehensive evaluation of real-world practice in an East Asian tertiary hospital. PloS One 8: e56011, 2013. 